\title{
Engineering Fairness? Market Design as a Resource for Social Justice Research
}

\author{
Sebastian Lotz ${ }^{1}$
}

Published online: 3 September 2015

(c) Springer Science+Business Media New York 2015

"It is that markets and marketplaces come in many forms, some of which don't conform to conventional
notions of markets, and some in which money may play little or no role" (Roth, 2015, p. 31).

Justice conflicts are prevalent across many instances of human interaction. Social justice research has a long history of addressing these issues and investigating them from a broad scope of disciplines such as psychology, sociology, political science, and economics. This book review essay introduces a relatively novel branch of economics-market design-to the audience of social justice researchers. It sketches its main thoughts and avenues of research along with applications in domains relevant for social justice research. In 2012, Alvin E. Roth shared the Bank of Sweden Prize in Memory of Alfred Nobel in Economic Science (commonly referred to as the Nobel Prize in Economics) with Lloyd E. Shapley for the theory of stable allocations and the practice of market design. In "Who gets what and Why? The New Economics of Matchmaking and Market Design" (2015, Eamon Dolan/ Houghton Mifflin Harcourt), Roth introduces the field to novices. The book provides a viable opportunity for social justice researchers to quickly familiarize themselves with some of the most relevant results of market design research before consulting the more technical literature that largely relies on game theory.

Social justice research has an inherent interest in how people, groups, or societies deal with competition over scarce resources. Many theories of social conflict suggest that at instances when people try to allocate scarce resources, individual (or group-based) egoistic inclinations lead to competitive action that ultimately result in social harm (Lind, 1995). A key challenge for social justice research is to overcome these harms. Market design and the related field of behavioral economic engineering

Sebastian Lotz

sebastian.lotz@gmail.com

1 Department of Sociology, Stanford University, 450 Serra Mall, Building 120, Stanford, CA 94305, USA 
(e.g., Bolton \& Ockenfels, 2012) designs real-world institutions and mechanisms that align individual incentives with the underlying goals set by societies, companies or other social groups. Market design is a hybrid between theory and application as it has a strong focus on (economic and related) theory but a strong interest in applying insights in the real world, leading to the connotation of the economist as an "engineer" (Bolton \& Ockenfels, 2012; Roth, 2002).

The aim of the essay is to raise the interest of social justice researchers in the economic discipline of market design and to promote market design thinking and related projects to the social justice community. The central question is whether we can use market design to "engineer" fair outcomes even when we make the assumption that people behave strongly self-interested. In these cases, can we prevent that competitive action leads to social harm, but instead to social benefits that may come in the form of sufficient organ availability, fair participation in education of many students, et cetera? Although the assumption of (strong) selfinterest can be regarded as cynical and at odds with many of the findings of psychological research on justice (e.g., van den Bos, Cropanzano, Kirk, Jasso, \& Okimoto, 2015, for a discussion of Vermunt, 2014), most of the areas that market design touches are "high-stakes" situations (e.g., altruistic organ donations, allocation of students to schools, job market entries for academics) where it is hard for fairness to emerge. This is owed to the fact that market design often addresses the allocation of non-divisible "goods", thus, disenabling "easy" solutions to justice conflicts (i.e., where, for instance, justice principles such as the equity, equality, or need offer a solution to the conflict). Selfless behavior in such "high-stakes" situation of non-divisible goods may mean not receiving a lifesaving organ, not getting into a preferred school, or not having a job after getting a $\mathrm{Ph} . \mathrm{D}$. It is clear that these situations make it particularly hard for fairness motivations to emerge as giving up your entitlement entirely is necessary to behave selflessly. In these types of situations, it is clear that social conflict can be best mitigated if efficiency is enhanced (i.e., more people can get what they want). This is an important goal of market design.

\section{Markets, Matching Markets, and Market Failures}

Roth (2015, Part I) starts his book highlighting the prevalence of markets in our lives. Markets are virtually everywhere and-contrary to common conception-do not always need money as an allocation mechanism. Markets are defined rather broadly: Whenever scarce resources are exchanged or matched, the exchange or match takes place in a market. Of particular interest to market designers are socalled matching markets, where the "things" that we choose also need to choose us. Among matching markets are the labor market, certain real-estate markets where the seller can freely choose a buyer, or admission to colleges and schools.

For instance, a company cannot just hire the person who costs least to perform a well-defined task, this person also has to choose the company as their employer. From the perspective of a university, the dean will not hire the individual who is willing to give a lecture on "social justice research" for the lowest price. Likewise, 
the smartest social justice researcher is (hopefully) not going to teach at the university who simply offers the most dollars for giving the lecture. Usually, when recruiting a new freshman class of 1000 people, an admissions officer will not just enroll the 1000 people who are willing to pay the most for their degree. Importantly, although these markets involve money (e.g., salaries, tuition, etc.), money is not the critical aspect in the transaction. Speaking in terms of economics, the price is not raised until demand equals supply. Rather, there is a selection process and finding a suitable match goes beyond price as an allocation tool.

That said, Roth (2015) describes matching markets as fundamentally different from commodity markets. In a commodity market, anyone can buy anything she/he wants; so long she/he can afford it. When people sell their stock market funds to buy a house, they generally do not care who buys these funds, just as grocery sellers are typically only interested that people pay for their groceries, but not who these paying people actually are. In commodity markets, the price does all the work. ${ }^{1}$ Importantly, markets can move from matching market to a commodity market, i.e., if a good is commoditized. Roth provides several examples of these in the book to illustrate that most markets are dynamic and might change in their inherent characteristics over time. For example, wheat was not always traded as a commodity, but started being commoditized after the Chicago Board of Trade introduced a classification grade and typology to make it comparable across producers and years, even enabling the sale of wheat that will only be produced in later years (e.g., selling wheat futures).

Many of the most prominent examples of market re-designs that are relevant to social justice research take place in matching markets, among them the market for kidney exchange (e.g., Rees et al., 2009), the school choice algorithms in Boston (Abdulkadiroğlu, Pathak, Roth, \& Sönmez, 2005), New York (Abdulkadiroğlu, Pathak, \& Roth, 2005, 2009), and other cities (Chen \& Kesten, 2012), as well as the job market placing programs for new doctors (Roth, 1991), lawyers/judicial clerks (Avery, Jolls, Posner, \& Roth, 2001), and Ph. D. economists (e.g., in Roth, 2008a).

Subsequently, Roth (2015) describes common reasons why markets fail due to the behavior of competitive market participants. Among these reasons are individual attempts to "jump the gun" in order to achieve an advantage over others in a "thick" marketplace consisting of many buyers and sellers, excessive speed in markets, as well as congestion of a market place (too many parties in a given timeframe). For instance, hiring a person earlier can lead to the hiring of better talents, but comes at the cost of premature hiring when the skillset of a prospective employee is not yet clear. In a competitive scenario, all firms might hire too early (e.g., hiring assistant professors up to a year before their graduation), because they fear that they will not be able to meet their hiring needs.

A second common failure is "speed." Especially in financial markets, arms races that lead to quick trading can lead to inefficiencies as resources are invested merely in the speed of trade. For instance, if trading at the level of milliseconds is allowed

\footnotetext{
${ }^{1}$ Importantly, in some labor markets, people are in fact seen as a commodity, especially with respect to low-skilled labor. Employers might not care who will do a low-skill task and only care about the price of it. While these labor markets have their own challenges in term of social justice, many high-skilled labor markets function as matching markets that face different, but equally important justice-issues.
} 
by a stock exchange, it can be reasonable for traders to invest in high-speed information technology that would be useless if trading were only allowed at the level of seconds. Finally, another failure of market speed consists of so-called exploding offers, which are job offers that have to be accepted before a certain deadline in order to still be valid. All of these market failures result from economic agents making competitively reasonable and optimal choices in the bounds of the law. For instance, hiring professors before they even graduate may be inefficient and unfair, but competitive parties may feel forced to play along.

\section{Examples of Market (Re-)designs}

Roth (2015) describes some of the most prominent examples of redesigned markets. Here, the most commonly known examples are given to show the reader two successful outcomes that market design has achieved and which are directly relevant to social justice research. ${ }^{2}$

\section{Kidney Exchange}

One example in which scarcity and justice conflicts are apparent is organ donation. Especially when deceased-donor organs are not sufficiently available, it takes more than a willing living donor to save a life or to make it more enjoyable (e.g., by sparing a kidney disease patient dialysis). There is a long list of criteria that have to match in order for an individual to qualify as a donor. Quite often, a patient cannot receive an organ due to the fact that none of their prospective donors are compatible. From psychological research on taboo tradeoffs ${ }^{3}$ (Tetlock, Kristel, Elson, Green, \& Lerner, 2000), we know that people find it particularly wrong to use money in these kinds of situations. The limited organs should clearly not be sold to the highest bidders. Although many illegal routes to purchased organs exist, societies across the globe almost unanimously reject the idea that human organs should be for sale. If societies try to reduce scarcity in such a market, they have to do so without the use of payments to donors, which may boost organ supply.

Although initially not intended for an application in the "kidney market," Shapley and Scarf (1974) formulated a mathematical thought experiment that exactly matches this problem of scarce kidneys: How can people trade indivisible goods if everyone needs just one, has one to trade, and can't use money? Roth and

\footnotetext{
${ }^{2}$ In general, I refer to „relevant for social justice research” when a market directly touches some sphere of individual justice concerns. Although most market designs can be named relevant from a justice perspective, not all of them directly involve people's concern for justice. For instance, market design is quite influential in spectrum auctions, in which governments allow mobile phone companies to bid for frequency. Although the revenue of such goes into a country's tax base and is then used for social security, education, etc., it is not directly justice-related. The agents that bid in such an auction (i.e., firms, with the help of game-theorists) try to behave in a highly self-interest and mathematically optimal manner. Also, market designs that affect trading in high-speed financial markets are only indirectly justice-relevant. Examples cited in the essay have a direct relation to people's concerns for justice.

${ }^{3}$ Roth refers to this general reluctance to trade everything for money as "repugnance" (e.g., Roth, 2008b).
} 
his colleagues identified that these people from the thought experiment could be viewed as incompatible patient-donor pairs. Shapley and Scarf (1974) found a mathematical solution to the riddle showing that for any given preference there is always a set of cyclical trades (e.g., "top-trading cycles") with the property that no group of people would rather go off and find a better outcome. Therefore, a given set of cyclical trades can achieve an efficient outcome-one that the group as a whole cannot outperform-without the use of money. Thus, the trading cycle achieves economic efficiency without giving up sacred values by using money as a means of exchange, an act that we might consider "taboo" (Tetlock et al., 2000). Roth and his colleagues used the approach of cyclical trades to re-design the way living donors can exchange organs in the USA (Ashlagi \& Roth, 2014; Roth, Sönmez, \& Ünver, 2004; 2005, 2007; Saidman, Roth, Sönmez, Ünver, \& Delmonico, 2006; Rees et al., 2009).

Importantly, kidney exchanges used to be performed only pairwise and simultaneously. The simultaneity was seen as critical to avoid that one party refuses a donation after his or her patient has received a life-saving organ. This malign incentive structure made non-simultaneous, longer organ donation chains impossible. The market redesign therefore focused also on reducing the risk of donating a kidney and subsequently losing the bargaining chip (i.e., a donor) if the other donor reneges on his or her gift. A reduction of that risk (e.g., by securing that victims of a reluctant donor receive an organ from another donor) enabled to move from pairwise donations to donation chains, therefore increasing the total number of transplants (see Rees et al., 2009 , for a detailed discussion of a never-ending altruistic donor chain). To sum up, the kidney exchange programs in the USA could be re-designed with the help of theoretical insights from game theory that have been applied to a particular matching market that carefully took real-world motivations (e.g., fear of reneging) into account when designing the rules that allowed an increase in transplants.

\section{School Choice}

Other prominent examples of market (re-)designs are the Boston and New York school matches (Abdulkadiroğlu, et al., 2005, 2009). Finding a suitable school is a very important decision for the progression of children's and teenagers' lives. In fact, getting into the "right" school is a key concern for many students and their parents as the quality of school education is seen as a significant driver of success in life. It is easily imaginable how not getting into a school that one likes (and seeing others getting into their preferred school) might cause severe justice conflicts in a community. In fact, I am confident that a content analysis of parents' and students' complaints about allocation to schools would put "unfairness" to the top of the list of arguments why the system is flawed.

Like organ donations, there is a large consensus that public schools cannot be filled based on the individual willingness or ability to pay for access. Allocation of students to schools is also a matching market without the use of money. The student has to choose the school just like the school has to offer a spot to the student, and there are numerous restrictions, similar to kidney exchange (e.g., distance to the school, siblings in the same school, diversity goals of the municipality, etc.) 
Many municipalities across the globe use(d) - from the perspective of market design_rules that put many students into schools that they did not want to go to. One common mistake was-and probably still is in many municipalities- that it is often wise for students to misreport their stated preference about which school to want to attend. For instance, if students can list only three preferences, the assignment rules may cause students to "game" the system. ${ }^{4}$ Roth (2015) describes in detail how the nuances of the rules never made it smart for students to report their preference honestly in Boston and New York. In addition, Roth shows how laboratory experiments could prove that families have most likely been misreporting their preferences due to the need of "gaming" the system (Chen \& Sönmez, 2006). It is not surprising that many students and their parents found the system unjust, both from a procedural and distributive justice perspective. A change in the rules (e.g., the introduction of deferred-acceptance algorithms, see Abdulkadiroğlu, et al., 2005) made it safe for students to report their true preferences and, thus, also increased the perception of procedural justice. Like in organ donation, the justice conflict could be mitigated following a change in the rules that mitigates perceived scarcity as more students could be assigned to a (truly) preferred school.

\section{Critique and Relevance: Market Design as a Resource for Social Justice Research?}

Upon reading the book, I had the impression that social justice research and market design provide mutual opportunities for each other. Market design has been ultrasuccessful as a field due to its high practical relevance for the solution of real-world justice conflicts, among them fundamental problems involving distributive justice of essential "goods" such as education, medical care, or job market participation, despite (or because) its theoretical rigor. Therefore, market design can be a useful new tool to a largely descriptive discipline that focuses on the psychology of justice. With the help of market design, (especially) psychological justice research cannot only identify justice conflicts, but also help to solve them by changing the institutional details that cause the conflict. The book is rather moot about the ability of market design to mitigate justice conflicts. However, Roth powerfully shows how questions of efficiency and-implicitly-procedural as well as distributive justice could be reconciled, whereas it is often seen as a trade-off (e.g., Okun, 2015). If many future social conflicts involve the distribution of scarce resources (e.g., water, safe living environments, energy), market design can be viewed as a key tool to mitigate such. Some recent work has already started to combine insights that are traditionally rooted in social justice research. For instance, re-designing the reputation system of Ebay (Bolton, Greiner, \& Ockenfels, 2013) followed some key

\footnotetext{
${ }^{4}$ Imagine such a rule in academia: Researchers across the fields would be allowed to submit their paper to a maximum of three journals. If it is repeatedly rejected, it will randomly be published in a journal of a bureaucrat's choosing. It is clear that submitting it to the three top journals is a quite risky endeavor. Quite likely, researchers would strategize about the best journal that their article will barely make it into and submission behavior would not at all signal preference for a particular journal. Worse, it may even be optimal to bribe the bureaucrat who will end up allocating articles to the journals (not) randomly.
} 
ideas about reciprocity and revenge (e.g., Gollwitzer \& Denzler, 2009) and the redesign of a global company's bonus program (Ockenfels, Sliwka, \& Werner, 2014) used theoretical insights that are central to our field, among them social comparison theory (e.g., Festinger, 1954), prospect theory (Kahneman \& Tversky, 1979), and relative deprivation theory (Stouffer et al., 1949).

Quite regularly, individuals are frustrated with organizational or societal settings that determine an outcome. I want to argue that many of our everyday frustrations are rooted in perceptions of injustice or feelings of unfair treatment. Roth describes this particularly well with respect to school choice. Before Boston and New York have received the new designs, it was clear to many parents that the system is flawed and needed to be "gamed." Naturally, rules that need to be "gamed" highlight shortcomings regarding procedural justice and give people the feedback that they may not be respected members in their community (e.g., Huo, Smith, Tyler, \& Lind, 1996; Lind \& Tyler, 1988, 1992). The redesign of school assignment did not only increase efficiency, but perhaps more importantly, the procedural justice in the system, giving children and their parents the feeling of being respected.

To sum up, I think that Roth's (2015) book "Who gets what and Why?" provides a viable opportunity for social justice scholars to familiarize themselves with the main ideas and selected achievements of market design. Wrapped up in personal anecdotes from an exciting research life, Roth manages to introduce a topic to a broader audience that has been traditionally dominated by complex gametheoretical jargon. The mere fact that market design has been influential in many fields, among them law, medicine, education, but also government auctions, makes the field interesting to our community. In his final conclusions, Roth states that markets are not a natural phenomenon, but human artifacts that can be maintained, improved, and sometimes even newly created. With justice being a core concern of humans, market design as a method to increase procedural and distributional justice can be a valuable add-on to the justice researcher's toolbox, especially when we adopt Roth's relatively broad conception of a market.

Acknowledgments This study was funded by the German Research Foundation (DFG) (Grant Number LO1826-1/2). I thank Al Roth for many fruitful discussion about market design and its relevance to other disciplines, among them social justice research.

\section{Compliance with Ethical Standards}

Conflict of interest Lotz declares that he has no conflict of interest.

Ethical standards This article does not contain any studies with human participants or animals performed by any of the authors.

\section{References}

Abdulkadiroğlu, A., Parag, A. P., \& Roth, A. E. (2009). Strategy-proofness versus efficiency in matching with indifferences: Redesigning the NYC high school match. American Economic Review, 99(5), 1954-1978. 
Abdulkadiroğlu, A., Pathak, P. A., \& Roth, A. E. (2005a). The New York City high school match. American Economic Review, 95(2), 364-367.

Abdulkadiroğlu, A., Pathak, P. A., Roth, A. E., \& Sönmez, T. (2005b). The Boston public school match. American Economic Review, 95(2), 368-371.

Ashlagi, I., \& Roth, A. E. (2012). New challenges in multihospital kidney exchange. The American Economic Review, 102(3), 354-359.

Ashlagi, I., \& Roth, A. E. (2014). Free riding and participation in large scale, multi-hospital kidney exchange. Theoretical Economics, 9(3), 817-863.

Avery, C., Jolls, C., Posner, R. A., \& Roth, A. E. (2001). The market for federal judicial law clerks. The University of Chicago Law Review, 793-902.

Bolton, G., Greiner, B., \& Ockenfels, A. (2013). Engineering trust: Reciprocity in the production of reputation information. Management Science, 59(2), 265-285.

Bolton, G. E., \& Ockenfels, A. (2012). Behavioral economic engineering. Journal of Economic Psychology, 33(3), 665-676.

Chen, Y., \& Kesten, O. (2012). From Boston to Shanghai to deferred acceptance: Theory and experiments on a family of school choice mechanisms. In Market Auctions (Ed.), Mechanisms, and their applications (pp. 58-59). Berlin: Springer.

Chen, Y., \& Sönmez, T. (2006). School choice: An experimental study. Journal of Economic theory, 127(1), 202-231.

Festinger, L. (1954). A theory of social comparison processes. Human Relations, 7(2), 117-140.

Gollwitzer, M., \& Denzler, M. (2009). What makes revenge sweet: Seeing the offender suffer or delivering a message? Journal of Experimental Social Psychology, 45(4), 840-844.

Huo, Y. J., Smith, H. J., Tyler, T. R., \& Lind, E. A. (1996). Superordinate identification, subgroup identification, and justice concerns: Is separatism the problem; is assimilation the answer? Psychological Science, 7(1), 40-45.

Kahneman, D., \& Tversky, A. (1979). Prospect theory: An analysis of decision under risk. Econometrica, 47(2), 263-291.

Lind, E. A. (1995). Social conflict and social justice: Lessons from the social psychology of justice judgments. Inaugural oration for the Leiden University Fund Chair in Social Conflict. Presented to the Faculty of the University, Leiden, the Netherlands, June, 1995. http://people.duke.edu/ alind/ INAUG.html. Last retrieval: July 28, 2015.

Lind, E. A., \& Tyler, T. R. (1988). The social psychology of procedural justice. Berlin: Springer.

Lind, E. A., \& Tyler, T. R. (1992). A relational model of authority in groups. Advances in Experimental Social Psychology, 25, 115-192.

Ockenfels, A., Sliwka, D., \& Werner, P. (2014). Bonus payments and reference point violations. Management Science, 61(7), 1496-1513.

Okun, A. M. (2015). Equality and efficiency: The big tradeoff. Washington, DC: Brookings Institution Press.

Rees, M. A., Kopke, J. E., Pelletier, R. P., Segev, D. L., Rutter, M. E., \& Fabrega, A. J. (2009). A nonsimultaneous, extended, altruistic-donor chain. New England Journal of Medicine, 360(11), 1096-1101.

Roth, A. E. (1991). A natural experiment in the organization of entry-level labor markets: Regional markets for new physicians and surgeons in the United Kingdom. American Economic Review, 81(3), 415-440.

Roth, A. E. (2002). The economist as engineer: Game theory, experimentation, and computation as tools for design economics. Econometrica, 70(4), 1341-1378.

Roth, A. E. (2008a). What have we learned from market design? The Economic Journal, 118(527), $285-310$.

Roth, A. E. (2008b). Repugnance as a constraint on markets. Journal of Economic Perspectives, 21(3), 37-52.

Roth, A. (2015). Who gets what and why: The new economics of matchmaking and market design. New York: Eamon Dolan/Houghton, Mifflin Harcourt.

Roth, A. E., Sönmez, T., \& Ünver, M. U. (2004). Kidney exchange. The Quarterly Journal of Economics, $119(2), 457-488$.

Roth, A. E., Sönmez, T., \& Ünver, M. U. (2005). A kidney exchange clearinghouse in New England. The American Economic Review, 95(2), 376-380.

Roth, A. E., Sönmez, T., \& Ünver, M. U. (2007). Efficient kidney exchange: Coincidence of wants in markets with compatibility-based preferences. The American Economic Review, 97(3), 828-851. 
Saidman, S. L., Roth, A. E., Sönmez, T., Ünver, M. U., \& Delmonico, F. L. (2006). Increasing the opportunity of live kidney donation by matching for two-and three-way exchanges. Transplantation, 81(5), 773-782.

Shapley, L., \& Scarf, H. (1974). On cores and indivisibility. Journal of Mathematical Economics, 1(1), 23-37.

Stouffer, S. A., Lumsdaine, A. A., Lumsdaine, M. H., Williams Jr., R. M., Smith, M. B., Janis, I. L., et al. (1949). The American soldier: Combat and its aftermath. Studies in social psychology in World War II (Vol. 2). Princeton, NJ: Princeton University Press.

Tetlock, P. E., Kristel, O. V., Elson, S. B., Green, M. C., \& Lerner, J. S. (2000). The psychology of the unthinkable: Taboo trade-offs, forbidden base rates, and heretical counterfactuals. Journal of Personality and Social Psychology, 78(5), 853-870.

Van den Bos, K., Cropanzano, R., Kirk, J., Jasso, G., \& Okimoto, T. G. (2015). Expanding the horizons of social justice research: Three essays on justice theory. Social Justice Research, 28(2), 229-246.

Vermunt, R. (2014). The good, the bad, and the just. How modern men shape their world. Farnham: Ashgate Publishing. 